Article

\title{
Development of a Spirit Drink Produced with Strawberry Tree (Arbutus unedo L.) Fruit and Honey
}

\author{
Ofélia Anjos 1,2,3 $\left(\mathbb{D}\right.$, Sara Canas ${ }^{4,5, *(\mathbb{D})}$, José Carlos Gonçalves ${ }^{1,3,6}(\mathbb{D})$ and Ilda Caldeira ${ }^{4,5}$ \\ 1 Instituto Politécnico de Castelo Branco, Escola Superior Agrária, 6001-909 Castelo Branco, Portugal; \\ ofelia@ipcb.pt (O.A.); jcgoncalves@ipcb.pt (J.C.G.) \\ 2 CEF, Instituto Superior de Agronomia, Universidade de Lisboa, 1349-017 Lisboa, Portugal \\ 3 Spectroscopy and Chromatography Laboratory, Centro de Biotecnologia de Plantas da Beira Interior, \\ 6001-909 Castelo Branco, Portugal \\ 4 Oenology Laboratory, Instituto Nacional de Investigação Agrária e Veterinária, Pólo de Dois Portos, \\ 2565-191 Dois Portos, Portugal; ilda.caldeira@iniav.pt \\ 5 MED-Mediterranean Institute for Agriculture, Environment and Development, Instituto de Formação \\ Avançada, Universidade de Évora, 7006-554 Évora, Portugal \\ 6 CERNAS, Centro de Recursos Naturais, Ambiente e Sociedade, Agricultural Sciences Research Group, \\ 6001-909 Castelo Branco, Portugal \\ * Correspondence: sara.canas@iniav.pt
}

Received: 15 April 2020; Accepted: 3 June 2020; Published: 5 June 2020

check for updates

\begin{abstract}
Food safety and diversification of agri-food products are increasingly important. A new spirit drink produced from the arbutus fruit (strawberry tree fruit) and honey was designed, taking advantage of the best features of these two ingredients and limiting the methanol content. This work reports the first approach to its development, considering in particular its chemical composition, especially the volatile components, and sensory properties. Methanol, acetaldehyde, ethyl acetate, and fusel alcohols were quantified and identified by GC-FID/GC-MS. Sensory analyses were performed by a trained panel. Promising results were obtained, showing that the new spirit has features close to those of honey spirit. Significantly lower contents of methanol, acetaldehyde, and ethyl acetate were observed in the new spirit compared to arbutus spirit (359.0 vs. $994.4 \mathrm{~g} / \mathrm{hL}$ of pure alcohol (P.A.), 20.5 vs. 25.6 g/hL P.A., and 35.5 vs. 53.9 g/hL P.A., respectively), which is advantageous from the food safety and quality perspectives. The total content of fusel alcohols in the new spirit was significantly lower than in honey spirit (261.4 vs. $388.85 \mathrm{~g} / \mathrm{hL}$ P.A.). Distinct aroma and flavor profiles were examined, but only four attributes were significantly different between the these spirit drinks: dried fruits, unctuous, varnish (although at very low perception), and sweet.
\end{abstract}

Keywords: spirit beverage; product development; strawberry tree fruit; bee product; volatile composition; sensory properties

\section{Introduction}

In Portugal, as in other Mediterranean countries, the strawberry tree (Arbutus unedo L.) is a valuable native species characterized by great resiliency and annual fruit production. Its fruit has a wide range of applications, including in folk medicine, as a raw material for pharmaceutical products, in dietary supplements and functional foods due to its richness in nutrients and bioactive compounds such as anthocyanins, flavonols, and phenolic acids [1-3]. In addition, it has been traditionally used for the production of jam, jelly, vinegar, and some alcoholic beverages. Regarding the last ones, the most renowned is the strawberry tree fruit spirit or arbutus spirit (designation adopted in this work), called "aguardente de medronho" in Portugal [4] and "koumaro" in Greece [5]. 
Several studies performed over the last decade revealed that the chemical composition of this spirit drink is strongly influenced by the degree of fruit ripeness, the fermentation conditions, and the distillation technology employed [4,6-8]. Among these factors, the timely and correct separation of the distillation fractions ("heads", "heart", and "tails") during the distillation process is of utmost importance for the volatile profile and, therefore, for the quality of the final product [4-6]. In this context, considerable attention has been devoted to the methanol concentration, resulting from the de-methylesterification of pectins, catalyzed by pectin methylesterases existing in the fruit [9], because of its harmful effect on human health, which is mainly associated with acute toxicity [10]. According to the European regulation on spirit drinks [11], the methanol concentration of arbutus spirit must be lower than $1000 \mathrm{~g} / \mathrm{hL}$ of pure alcohol (P.A.). Despite tight controls during the production process, most arbutus spirits still exhibit levels of methanol close to the legal limit, as reported in the aforementioned research works $[4,7,12]$.

Honey is a healthy product mainly composed of sugars (mono-, di-, and trisaccharides) [13] and several other substances such as proteins, lipids, vitamins, minerals, and phenolic compounds [14,15]. It has been used for centuries not only as food but also as a food ingredient [16] in beverages [17-19] and for medical and cosmetic purposes [20]. Honey spirit is produced by distillation of fermented honey. Fermentation is the most critical step in the spirit's production process; special care is required in the selection and concentration of yeasts, due to the high sugar content of the raw material [17,21-23]. According to the European regulation [11], honey spirit shall have a minimum alcohol strength of $35 \%$ and present sensory properties derived from honey, that is, most volatile compounds of honey should be preserved in the spirit, confirming the use of honey as a raw material for its preparation. The most abundant volatile compounds in honey spirit are saturated alcohols, ethyl esters of saturated fatty acids, and terpenes [24]. The low methanol content, residual in most of these spirits, should be highlighted $[19,25]$. Regarding the sensory features, Anjos et al. [25] reported, for the first time, a list of 98 attributes, the most prominent of which were olfactory attributes (fruity, floral, sweet and vegetative/herbaceous) and flavor attributes (smoky, sweet, and bitter).

The diversification of agri-food products, including spirit drinks, is increasingly important in the face of a global and more competitive market with more informed and demanding consumers. In this sense, new high-quality products, guaranteeing food safety, are of great significance for industrial and rural sustainability. This challenge was the main driver of the present work. Bearing in mind the interest in using the above-mentioned raw materials to take advantage of their best features and to decrease the methanol content in the resulting spirit, it is imperative to examine the impact of their simultaneous fermentation and distillation on the resulting spirit's quality. Thus, this paper is focused on determining the chemical composition, especially regarding the volatile compounds, and sensory properties of a new spirit drink based on strawberry tree fruit and honey and on comparing them with those of arbutus spirit and honey spirit.

\section{Materials and Methods}

\subsection{Samples}

Two batches, one of strawberry tree fruits and another of honey, both produced in the center of Portugal, were used in three preparation modalities to obtain three kinds of spirit drinks: (i) arbutus spirit; (ii) blend of strawberry tree fruit and honey spirit; (iii) honey spirit. Two replicates of each preparation were performed.

Alcoholic fermentation was performed in six 100 L polyvinylchloride (PVC) containers: (i) the fermentation of the strawberry tree fruit was carried out, as traditionally, without water addition and without yeast inoculation, in duplicate; (ii) the simultaneous fermentation of strawberry tree fruit and honey was also made without water addition and without yeast inoculation, in duplicate. The blend of strawberry tree fruit and honey contained $50 \%$ of each ingredient; (iii) the fermentation of honey was made with honey and water until the mixture reached $27 \%$ of total soluble solids, in duplicate; 
inoculation with commercial Saccharomyces cerevisiae (Enartis Ferm SC, Enartis, Porto, Portugal) was made. The containers were closed with airlocks but held a $\mathrm{CO}_{2}$ escape valve. The fermentation took place at room temperature until the end of carbon dioxide production. Each fermented batch was distilled separately, and six batch distillations were performed (two of the strawberry tree fruit, two of strawberry tree fruit and honey, and two of honey). It was used an industrial distillation unit (Vieirinox, Aveiro, Portugal), made of copper, using entrainment in steam, and equipped with a boiler for steam production, a $200 \mathrm{~L}$ copper still provided with lids with hermetic closure, a lenticular dephlegmator, a condenser composed of stainless steel tubes in vertical position, with continuous water inlet and outlet. At the outlet, an alcoholmeter was placed to monitor the alcohol strength. The heating power was set to obtain an initial average distillation rate of about $10 \mathrm{~L} / \mathrm{h}$.

The distillates' samples used in this study corresponded to the "heart" fraction; the first and the last distillation fractions ("heads" and "tails", respectively) were discarded. This procedure is a common practice in spirits production to purify the distillate, because the acetaldehyde content is usually higher in the "heads", and the methanol content in commonly higher in the "tails" [26]. The separation of fractions was made according to the procedure proposed by Botelho et al. [4], in which the "heart" is collected between $70 \%$ and $35 \%$ v/v of ethanol.

\subsection{Chemical Analysis}

Several analytical determinations were performed (in duplicate) in order to characterize the three kinds of spirit drinks produced, i.e., the blend of strawberry tree fruit and honey spirit, the arbutus spirit, and the honey spirit.

Alcohol strength was determined by distillation and electronic densimetry, using an electronic densimeter (Model 5000 DMA; Anton Paar, Graz, Austria), according to the OIV method [27]. The results are expressed as a volumetric percentage of ethanol in the spirit drink.

Dry extract was assessed by gravimetry, according to the OIV method [27]. The results are expressed as grams per litter.

Total acidity (by colorimetric titration), fixed acidity (by colorimetric titration of the water solution of the dry extract), and volatile acidity (total acidity minus fixed acidity) were determined according to the corresponding OIV methods [27]. The results are expressed as grams of acetic acid per liter.

pH was analyzed using a potentiometer (micro pH2002, Crison, Barcelona, Spain), according to the OIV method [27].

Methanol, acetaldehyde, ethyl acetate, and fusel alcohols were analyzed by gas chromatography with flame ionization detection GC-FID using an internal standard (1 mL of 4-methyl-2-pentanol with $9 \mathrm{~mL}$ of sample), according to the method described and validated by Luis et al. [28]. The results were expressed as $\mathrm{g} / \mathrm{hL}$ of P.A. The volatile compounds identification was performed through GC-MS (Magnum, Finnigan Mat, San Jose, USA). The GC was equipped with a fused silica capillary column of polyethylene glycol (INNOWAX of J \& W Scientific, Folsom, CA, USA), 30 m, 0.25 mm i.d., $0.25-\mu \mathrm{m}$ film thickness. The operating conditions were as follows: injector and interface temperature, $250{ }^{\circ} \mathrm{C}$; carrier gas helium (inlet pressure $83 \mathrm{kPa}$ and split ratio 1:60); oven temperature program: $3.5^{\circ} \mathrm{C} / \mathrm{min}$ from $35^{\circ} \mathrm{C}$ (6 min isothermal) until $55^{\circ} \mathrm{C}, 7.5^{\circ} \mathrm{C} / \mathrm{min}$ until $130{ }^{\circ} \mathrm{C}, 5{ }^{\circ} \mathrm{C} / \mathrm{min}$ until $210{ }^{\circ} \mathrm{C}$, and held at this temperature for $30 \mathrm{~min}$; volume injected $0.4 \mu \mathrm{L}$. The mass spectrometer was operated in the electron impact mode at $70 \mathrm{eV}$, scanning the range $\mathrm{m} / \mathrm{z} 40-340$ in a $1^{-\mathrm{s}}$ cycle. The identification of volatile compounds was achieved by comparison of the GC retention times and mass spectra with those of pure standard compounds. All mass spectra were also compared with those of the National Institute of Standards and Technology (NIST) database.

\subsection{Sensory Analysis}

A descriptive sensory analysis of the three spirit drinks was performed by a tasting panel comprising 10 trained tasters (seven women and three men, aged from 24 to 72 years), with several years of experience in the assessment of alcoholic beverages. The tasters were trained according to the 
international standards [29], including the detection and recognition of odors and tastes, as well as the use of the score sheet's scales. Prior to this study, training sessions were carried out to assess several flavor standards. The spirit drinks were evaluated by using a score sheet previously developed.

The sensory score sheet included 35 attributes [25]: 5 visual attributes (yellow-green, yellow-straw, golden, topaz, and greenish); 21 olfactory attributes (alcohol, fruity, honey, sweet, floral, menthol, woody, dried fruits, baker's yeast, bread, smoke, toasted/burned, vanilla, caramel, coffee, herbaceous, tails, varnish/ethyl acetate, oily, heads, and soap); 9 gustatory attributes (sweet, bitter, smooth, burning, roughness, body, unctuous, balance, and flavor persistence). The tasters were asked to provide the intensity of each attribute using a structured scale varying from 0 (no perception) to 5 (highest perception). They were also asked to evaluate the overall quality of the spirit drinks between 0 (without quality) and 20 (maximum quality). The overall quality corresponds to the taster perception about the beverage, taking into account the absence or presence of defects and the balance of different attributes.

The descriptive sensory analysis was performed in a sensory room, in the morning (10 a.m.). Samples were tasted in a randomized balanced order to eliminate the first-order carry-over effects and served as $30 \mathrm{~mL}$ in wine tasting glasses [30], at room temperature $\left(21^{\circ} \mathrm{C} \pm 1{ }^{\circ} \mathrm{C}\right)$, and under white natural light. Water was supplied for mouth cleaning between samples.

\subsection{Statistical Analysis}

One-way analysis of variance (ANOVA) and a Scheffé post-hoc test with $95 \%$ confidence interval were performed to examine differences in the chemical composition and sensory properties of the spirit drinks under study. A principal component analysis (PCA) was carried out aiming at an overall evaluation of the chemical data. All calculations were made using statistic Statistics ${ }^{\circledR}$ version 7.0.

\section{Results and Discussion}

\subsection{Chemical Composition of the Spirit Drinks}

The ANOVA results for the chemical characteristics of the strawberry tree fruit and honey spirit (the new spirit drink), arbutus spirit, and honey spirit are shown in Table 1.

Table 1. Chemical characteristics of the new spirit made with strawberry tree fruit and honey (50:50 $v / v)$, arbutus spirit, and honey spirit.

\begin{tabular}{|c|c|c|c|}
\hline & $\begin{array}{c}\text { Strawberry Tree Fruit } \\
\text { and Honey Spirit }\end{array}$ & Arbutus Spirit & Honey Spirit \\
\hline Alcohol strength $(\% v / v)$ & $50.96 \pm 0.03^{b}$ & $42.42 \pm 0.01^{\mathrm{a}}$ & $51.44 \pm 0.03^{c}$ \\
\hline Dry extract $(\mathrm{g} / \mathrm{L})$ & $0.02 \pm 0.00^{\mathrm{c}}$ & $0.00 \pm 0.00^{\mathrm{a}}$ & $0.01 \pm 0.00^{b}$ \\
\hline $\mathrm{pH}$ & $4.81 \pm 0.01^{\mathrm{c}}$ & $4.17 \pm 0.01^{\mathrm{a}}$ & $4.63 \pm 0.01^{b}$ \\
\hline Total acidity (g of acetic acid/L) & $0.115 \pm 0.001^{\mathrm{a}}$ & $0.242 \pm 0.001^{b}$ & $0.120 \pm 0.001^{\mathrm{a}}$ \\
\hline Fixed acidity (g of acetic acid/L) & $0.019 \pm 0.002^{\mathrm{a}}$ & $0.020 \pm 0.002^{\mathrm{a}}$ & $0.016 \pm 0.001^{\mathrm{a}}$ \\
\hline Volatile acidity (g of acetic acid/L) & $0.096 \pm 0.001^{\mathrm{a}}$ & $0.220 \pm 0.001^{b}$ & $0.104 \pm 0.001^{\mathrm{a}}$ \\
\hline Methanol (g/hL P.A.) & $359.00 \pm 0.33^{b}$ & $994.42 \pm 5.15^{c}$ & $16.94 \pm 1.14^{\mathrm{a}}$ \\
\hline Acetaldehyde (g/hL P.A.) & $20.55 \pm 0.42^{b}$ & $25.56 \pm 1.64^{\mathrm{c}}$ & $3.23 \pm 0.13^{\mathrm{a}}$ \\
\hline Ethyl acetate (g/hL P.A.) & $35.53 \pm 0.67^{b}$ & $53.87 \pm 0.69^{c}$ & $29.74 \pm 0.62^{a}$ \\
\hline 2-Butanol (g/hL P.A.) & nd & $0.16 \pm 0.01$ & nd \\
\hline 1-Propanol (g/hL P.A.) & $31.28 \pm 0.23^{b}$ & $9.51 \pm 0.10^{\mathrm{a}}$ & $36.66 \pm 0.62^{c}$ \\
\hline 2-Methyl-1-Propanol (g/hL P.A.) & $34.74 \pm 0.12^{\mathrm{a}}$ & $51.99 \pm 0.29^{c}$ & $44.84 \pm 0.24^{b}$ \\
\hline 1-Butanol (g/hL P.A.) & $0.74 \pm 0.01^{\mathrm{b}}$ & $0.17 \pm 0.05^{\mathrm{a}}$ & $0.85 \pm 0.02^{b}$ \\
\hline 2+3-Methyl-1-Butanol (g/hL P.A.) & $194.61 \pm 1.92^{\mathrm{a}}$ & $185.15 \pm 1.58^{\mathrm{a}}$ & $306.51 \pm 5.35^{b}$ \\
\hline Total fusel alcohols (g/hL P.A.) * & $261.37 \pm 2.27^{\mathrm{a}}$ & $246.97 \pm 2.04^{\mathrm{a}}$ & $388.85 \pm 6.23^{b}$ \\
\hline
\end{tabular}

Results expressed as mean \pm standard deviation; values within the same row followed by different letters $(a, b, c)$ are significantly different $(p<0.05)$ according to Scheffé's test; nd—not detected; P.A.: pure alcohol; ${ }^{*}$ 1-Propanol + 2-Methyl-1-Propanol + 1-Butanol + 2+3-Methyl-1-Butanol. 
The alcohol strength of the new spirit drink, as well as those of the arbutus spirit and honey spirit, were above the minimum required by the European regulation [11]. The spirit drinks made from the strawberry tree fruit also had alcohol strength higher than the minimum of $42 \%$ required by the Portuguese regulation for arbutus spirit [31]. Moreover, the results are in accordance with those previously obtained by Caldeira et al. [7] for arbutus spirit and by Anjos et al. $[19,25]$ for honey spirit.

The dry extract was almost null in all spirit drinks, reflecting a good distillation process.

The $\mathrm{pH}$ values were similar for the three beverages. Regarding the raw materials used, honey usually presents a lower $\mathrm{pH}$ than the strawberry tree fruit [2,32]. The higher $\mathrm{pH}$ of the honey spirit with respect to that of the arbutus one derived from the considerable quantity of water added to make the fermentation process possible. Besides, the $\mathrm{pH}$ values were within the range observed for other commercial spirits. Anjos et al. [25] found values ranging between 2.47 and 4.49 for honey spirits, and Caldeira et al. [7] reported values ranging from 3.83 to 4.48 for arbutus spirits. Botelho et al. [4] obtained $\mathrm{pH}$ values ranging between 3.50 and 3.72 for arbutus spirits produced from fruits with different ripeness degrees.

The total acidity of the spirit drinks under study was mainly due to volatile acidity. The new spirit exhibited the lowest acidity, not significantly different from that of the honey spirit, while the arbutus spirit presented a significantly higher acidity. The results for arbutus spirit and honey spirit are in accordance with those of previous works [4,25].

Regarding the volatile composition, it should be emphasized the significantly higher methanol content in arbutus spirit (994.42 g/hL P.A.), which was slightly below the legal limit (1000 g/hL P.A.). Similar results are reported in the literature [4,5,7]. Botelho et al. [4] observed a positive relationship between the ripeness degree of the strawberry tree fruit and the methanol content of arbutus spirit. Indeed, as aforementioned, this alcohol derives from the de-methylesterification of pectins catalyzed by pectin methylesterases [9], whose activity increases during fruit ripening [33]. In addition, the methanol level in fruit distillates also depends on other key factors, such as fruit's storage time and temperature and duration of the fermentation and distillation processes [5-8,34-36]. The honey spirit had a significantly lower methanol content ( $16.94 \mathrm{~g} / \mathrm{hL}$ P.A.), as expected, which has been ascribed to the low concentration of pollen existing in the raw material [25]. In fact, Roldán et al. [37] highlighted the impact of the enzymatic hydrolysis of pollen pectins during fermentation on the methanol content of mead.

It is noteworthy the significantly lower level of methanol in the new spirit ( $359.00 \mathrm{~g} / \mathrm{hL}$ P.A.) compared to the arbutus spirit. Although 50\% of each raw material (strawberry tree fruits and honey) was used, there was a $64 \%$ reduction in methanol content compared to the latter. This aspect has a notable interest from the food safety point of view. The explanation of this feature may lie in the inhibition of pectin methylesterases from the strawberry tree fruit by some proteins of honey. Indeed, Giovane et al. [38] and Wormit and Usadel [9] reported that several proteins acting as pectin methylesterase inhibitors have been found in different plant species such as grapevine, field mustard, rice, flax and in fruits such as kiwi, banana, orange and tomato. Wormit and Usadel [9] also described the presence of pectin methylesterase inhibitors in floral organs, particularly in pollen tubes, and in pollen. Considering the honey production process by bees, it is plausible that such inhibitors existing in flowers and pollen are transferred to honey. On the other hand, the interaction between honey enzymes, whose diversity and abundance have been pointed out [39], with pectin methylesterases from the strawberry tree fruit is also likely. Further studies are required to confirm these hypotheses.

Acetaldehyde and ethyl acetate concentrations were significantly higher in arbutus spirit $(25.56 \mathrm{~g} / \mathrm{hL}$ P.A. and $53.87 \mathrm{~g} / \mathrm{hL}$ P.A., respectively) than in the other spirit drinks. However, these concentrations are acceptable and lower than those observed in previous studies $[4,5,12]$. These volatile compounds result from oxidative processes in aerobic conditions, and their contents depend on the ripeness degree of the strawberry tree fruit [4], the fermentation conditions, and the separation of "head" fractions during distillation $[5,7,35]$. The lowest levels found in honey spirit ( $3.23 \mathrm{~g} / \mathrm{hL}$ P.A. and $29.74 \mathrm{~g} / \mathrm{hL}$ P.A., respectively) are in line with those observed by Anjos et al. [19,25] in some artisanal 
spirits. Such feature is likely due to the water added to honey before fermentation, which may hinder oxidation and esterification reactions, as argued by Caldeira et al. [7] in a study on strawberry tree fruit fermentation with and without water. The new spirit drink exhibited intermediate contents of acetaldehyde ( $20.55 \mathrm{~g} / \mathrm{hL}$ P.A.) and ethyl acetate ( $35.53 \mathrm{~g} / \mathrm{hL}$ P.A.), which may have resulted from less favorable conditions for oxidation and esterification created by mixing strawberry tree fruits and honey compared with those achieved in the fruit mash used for arbutus spirit production. According to the literature, higher concentrations of these compounds are associated with off-flavors, which are negatively correlated with the final product quality [4]: oxidized, crushed apple for acetaldehyde, and glue, varnish for ethyl acetate [12]. All spirit drinks under study presented moderate content of these compounds, which was reflected in the sensory assessment.

Concerning the fusel alcohols, which are mainly produced by yeasts and bacteria during fermentation and whose concentration in alcoholic beverages is quantitatively relevant [40], a significantly higher content was found in honey spirit (388.85 g/hL P.A.) than in the new spirit ( $261.37 \mathrm{~g} / \mathrm{hL}$ P.A.) and arbutus spirit (246.97 g/hL P.A.). These differences are likely related to the specific microbiota involved in the fermentation of each raw material $[4,7]$. The arbutus spirit's content of fusel alcohols was similar to those obtained in previous studies $[4,5]$. The highest level found in honey spirit may have been induced by the water added before fermentation, due to its influence on microorganisms' metabolism [41], as observed by Caldeira et al. [7] in studies of arbutus spirit's fermentation. Despite the differences found, all spirit drinks exhibited an acceptable level of total fusel alcohols, which may impart positive sensory attributes.

A detailed analysis of fusel alcohols showed that 2-butanol was only detected in arbutus spirit but at a very low level (0.16 g/hL P.A.). Similarly, the content of 1-butanol was very low in all spirit drinks, especially in the arbutus one $(0.17 \mathrm{~g} / \mathrm{hL}$ P.A.). These features seem to reflect the microbiological stability of the raw materials used [35]. In addition, 2-propen-1-ol was not detected, and the contents of 1-propanol and 2+3-methyl-1-butanol (isoamyl alcohols) were significantly higher in honey spirit than in drinks obtained from the strawberry tree fruit. Water added to honey may explain such distinct behavior, as suggested by Caldeira et al. [7]. Significant differences were also found for 2-methyl-1-propanol content in these spirit drinks: arbutus spirit had a higher content than honey spirit, whose content was higher than in the new spirit.

Complementarily, the results of PCA (standardized biplot of loadings and scores) performed with the above-mentioned chemical data confirmed the differentiation of the three spirit drinks according to the raw materials used (Figure 1).

The two principal components explained $97.0 \%$ of the total variance. The first component, accounting for $75.0 \%$ of the total variance, allowed the separation between the arbutus spirit and the other spirit drinks. Samples of new sprit $(\mathrm{SH})$ and honey spirit $(\mathrm{H})$ are placed at positive values of this component, while arbutus spirit (S) is located at negative values. PC1 had a strong positive vector loading for alcohol strength, $\mathrm{pH}$, 1-propanol, and 2+3-methyl-1-butanol, and a strong negative vector loading for total acidity, volatile acidity, methanol, acetaldehyde, ethyl acetate, and 2-methyl-1-propanol, which is consistent with the ANOVA results.

These results showed that the new spirit drink presented an interesting chemical composition, with intermediate characteristics between the arbutus spirit and the honey spirit, but closer to the latter one. Actually, a quite lower concentration of methanol than in arbutus spirit, induced by the honey added to the strawberry tree fruit mash before fermentation, is a remarkable feature of this new spirit drink. In addition, lower levels of acetaldehyde and ethyl acetate are also distinctive and positive features of the new product. 


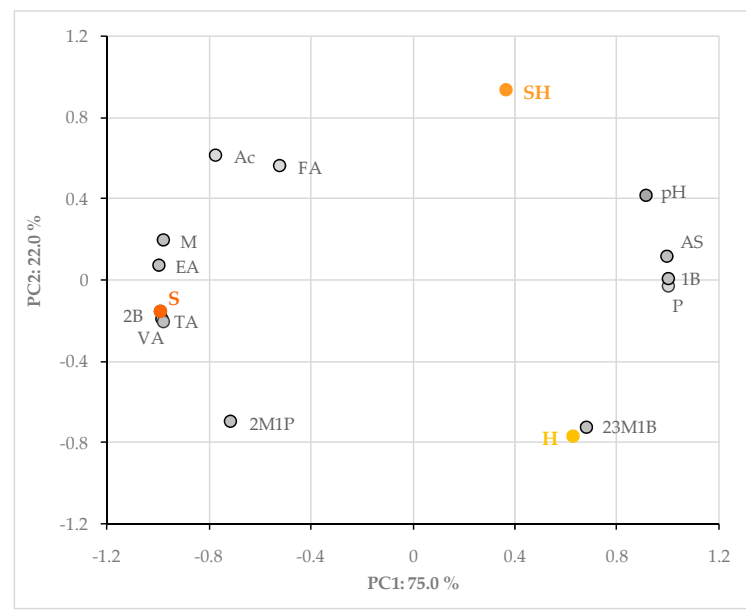

Figure 1. Principal component analysis (PCA) plot with all spirit drinks and chemical characteristics. AS, Alcohol strength; TA, Total acidity; FA, Fixed acidity; VA, Volatile acidity; M, Methanol; Ac, Acetaldehyde; EA, Ethyl acetate; 2M1P, 2-Methyl-1-Propanol; P, 2-propen-1-ol; 1B, 1-Butanol; 23M1B, 2+3-Methyl-1-Butanol. SH, new spirit drink made with strawberry tree fruit and honey; $\mathrm{S}$, arbutus spirit; $\mathrm{H}$, honey spirit.

\subsection{Sensory Properties of the Spirit Drinks}

The results of the descriptive sensory analysis of the strawberry tree fruit and honey spirit (new spirit drink), arbutus spirit, and honey spirit showed that the five visual attributes were scored with zero because these beverages were colorless. Hence, only the aroma and flavor profiles of the three beverages are shown in Figure 2.

Among the 21 olfactory attributes included in the sensory score sheet, 5 were almost null, and were therefore discarded: woody, bread, caramel, coffee, and heads. All nine gustatory attributes were scored.

Examining the sensory profile of these spirit drinks, similar intensities of the attributes alcohol, smooth, and flavor persistence were found. The arbutus spirit (S) showed slightly higher intensities for fruity, oily, and balance than the other drinks, while the honey spirit $(\mathrm{H})$ had slightly higher intensities for honey, sweet (aroma), soap, burning, and roughness than the others. Interestingly, the new spirit drink (SH) exhibited intermediate aroma and flavor profiles, though closer to those of honey spirit, as observed for the chemical composition; it also revealed slightly higher intensities for floral and toasted/burned, and slightly lower intensity for herbaceous than the other drinks.

According to Anjos et al. [25], sweet and herbaceous are common sensory attributes of honey spirits. Herbaceous has also been frequently used to characterize other alcoholic beverages, such as whisky and wine spirit [42,43]. In addition, the fruity and floral attributes of this kind of spirit drinks were ascribed to several esters and terpenic compounds/other esters, respectively [24].

Among the attributes scored, the ANOVA results showed that only dried fruits, varnish/ethyl acetate, sweet (flavor), and unctuous were significantly different for the three beverages (Figure 3).

The arbutus spirit (S) showed significantly higher intensities for the attributes dried fruits and unctuous than the other beverages. Conversely, the honey spirit $(\mathrm{H})$ had significantly higher intensities for varnish/ethyl acetate and sweet (flavor). The new spirit (SH) presented intermediate sensory attributes' intensities. Despite the observed differences, the very low perception of varnish (between 0.1 and 1) in all beverages should be stressed, which is consistent with their moderate concentrations of ethyl acetate. Inversely, there was a noticeable intensity of sweet, especially in the flavor, for all spirit drinks. According to Anjos et al. [25], sweet is very often used to describe the honey spirits' flavor.

To the best of our knowledge, there is no information available in the literature about the sensory properties of arbutus spirit. For this reason, despite the great interest in comparing the results obtained with others, it is not possible to do so. 


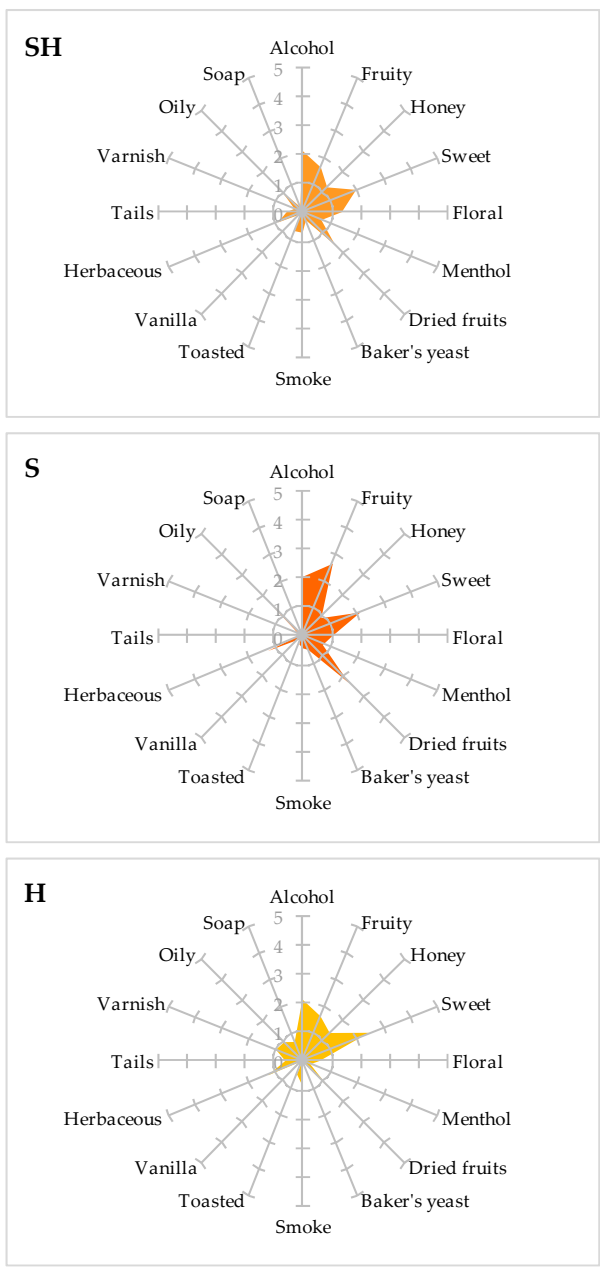

(a)
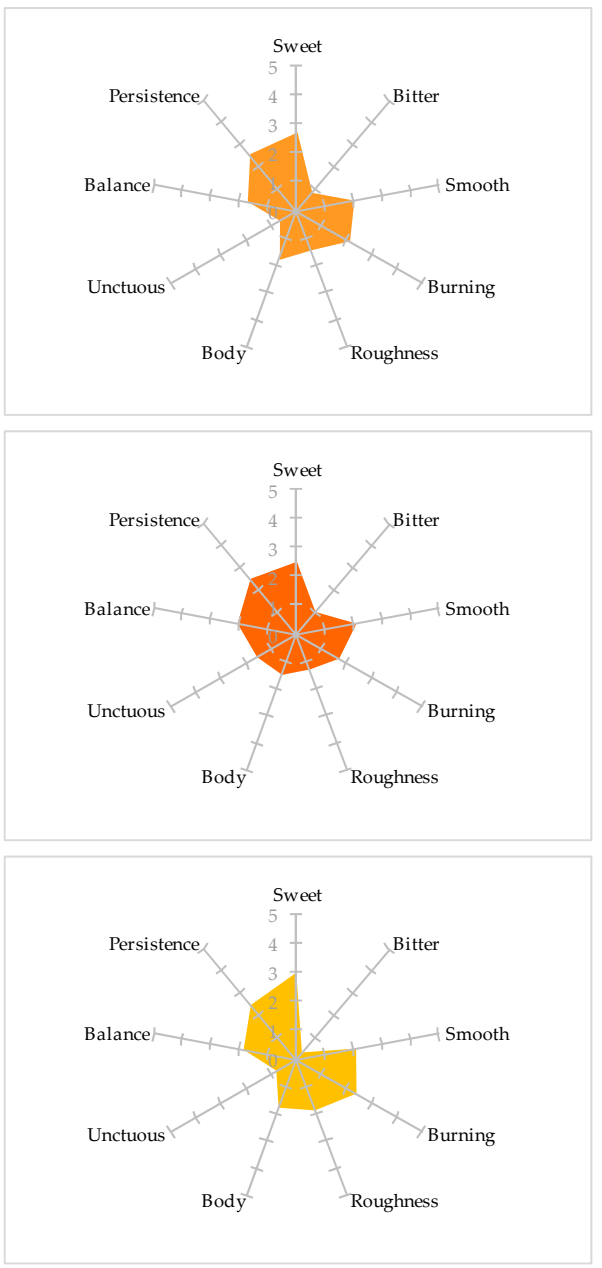

(b)

Figure 2. Aroma (a) and flavor (b) profiles based on the average panel attributes' scores of the spirit drinks ( $\mathrm{SH}$, new spirit drink made with strawberry tree fruit and honey; $\mathrm{S}$, arbutus spirit; $\mathrm{H}$, honey spirit).

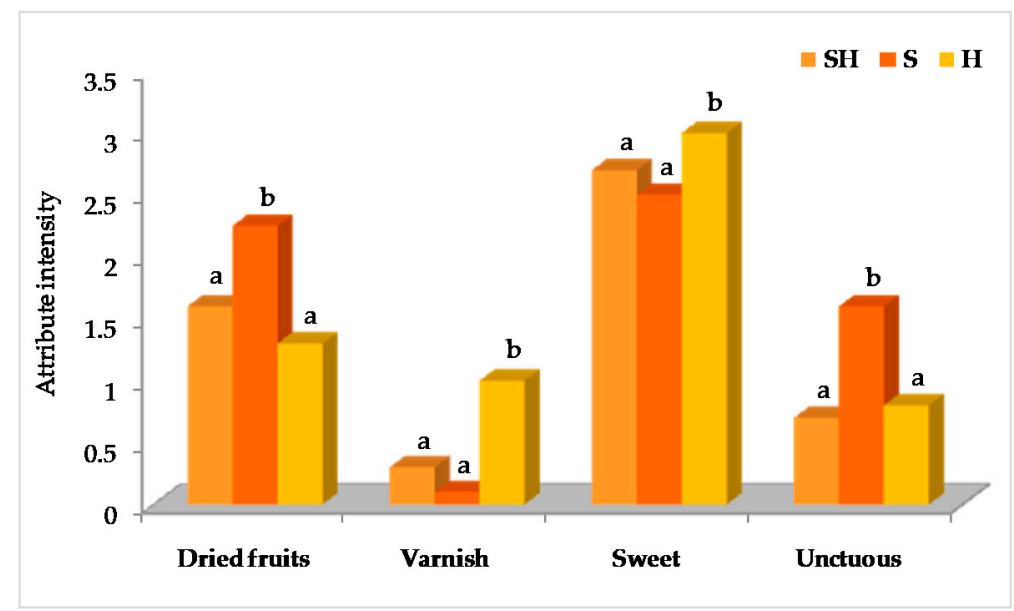

Figure 3. Results of the mean comparison test of the four sensory attributes significantly different in the spirit drinks. For each attribute, columns with different letters $(a, b)$ are significantly different according to Scheffé's test. 
Regarding the overall quality, the trained panel rated all drinks as very good ( $>12)$ : new spirit score 12.6 \pm 1.1 ; arbutus spirit score $13.2 \pm 1.1$; honey spirit score 12.6 \pm 1.5 . Differences between these scores were not significant.

Taking into account the chemical composition and the sensory profile, interesting and promising evaluations were attained by the new spirit drink compared to the arbutus spirit and the honey spirit.

\section{Conclusions}

This work on the development of a new spirit drink produced from the simultaneous fermentation of strawberry tree fruit and honey ( $50 \%$ of each mash) led to interesting and promising results. Actually, the new spirit showed intermediate chemical characteristics and sensory properties to those of spirit drinks resulting from each raw material (arbutus spirit and honey spirit), but closer to those of the honey spirit. It is noteworthy the significantly lower contents of methanol, acetaldehyde, and ethyl acetate in the new spirit compared to the arbutus spirit, which is advantageous from the food safety and quality points of view. According to the sensory attributes scored in the descriptive analysis made by a trained panel, different aroma and flavor profiles were exhibited by the three spirit drinks, but significant differences were only found for the attributes dried fruits, varnish/ethyl acetate, sweet (flavor), and unctuous. Similar intensities of dried fruits and unctuous were presented by the new spirit and honey spirit, whereas similar intensities of varnish/ethyl acetate (although at very low perception) and sweet were shown by the new spirit and arbutus spirit.

Further research is needed to study different formulations and their impact on the chemical composition, including the full volatile profile, and sensory properties of the new beverage towards its optimization.

Author Contributions: Conceptualization, O.A. and I.C.; methodology, O.A. and I.C.; formal analysis, O.A., I.C., and S.C.; investigation, O.A. and I.C.; writing-original draft preparation, O.A., I.C., and J.C.G.; writing-review and editing, S.C.; funding acquisition, O.A. and J.C.G. All authors have read and agreed to the published version of the manuscript.

Funding: This research was funded by Centro 2020 program and European Regional Funds (FEDER) within the framework of the Platform for Innovation of Strawberry Tree Project and the research unit funded by FCT: Centro de Estudos Florestais (UIDB/00239/2020); MED—Foundation for Science and Technology (UIDB/05183/2020); CERNAS—Research Centre for Natural Resources, Environment and Society (UID/AMB/00681/2019).

Acknowledgments: The authors thank Teresa Delgado for her help in the industrial samples preparation, Destilaria Oleiros for the distillate preparations, Luis Américo for supplying the strawberry trees fruit and his help in the fermentation process, Amélia Soares, Deolinda Mota, and Otília Cerveira for their technical support in the chemical and sensory analyses, and the INIAV-Dois Portos sensory panel for the descriptive analysis.

Conflicts of Interest: The authors declare no conflict of interest.

\section{References}

1. Fortalezas, S.; Tavares, L.; Pimpão, R.; Tyagi, M.; Pontes, V.; Alves, P.M.; McDougall, G.; Stewart, D.; Ferreira, R.B.; Santos, C.N. Antioxidant properties and neuroprotective capacity of strawberry tree fruit (Arbutus unedo). Nutrients 2010, 2, 214-229. [CrossRef] [PubMed]

2. Ruiz-Rodríguez, B.M.; Morales, P.; Fernández-Ruiz, V.; Sánchez-Mata, M.-C.; Cámara, M.; Díez-Marqués, C.; Pardo-de-Santayana, M.; Molina, M.; Tardío, J. Valorization of wild strawberry-tree fruits (Arbutus unedo L.) through nutritional assessment and natural production data. Food Res. Int. 2011, 44, 1244-1253. [CrossRef]

3. Morgado, S.; Morgado, M.; Plácido, A.I.; Roque, F.; Duarte, A.P. Arbutus unedo L.: From traditional medicine to potential uses in modern pharmacotherapy. J. Ethopharmacol. 2018, 225, 90-102. [CrossRef] [PubMed]

4. Botelho, G.; Gomes, F.; Ferreira, F.M.; Caldeira, I. Influence of maturation degree of Arbutus (Arbutus unedo L.) fruits in spirit composition and quality. Int. J. Agric. Biol. Eng. 2015, 9, 615-620.

5. Soufleros, E.H.; Mygdalia, S.A.; Natskoulis, P. Production process and characterization of the traditional Greek fruit distillate "Koumaro" by aromatic and mineral composition. J. Food Compos. Anal. 2005, 18, 699-716. [CrossRef] 
6. Santo, D.E.; Galego, L.; Gonçalves, T.; Quintas, C. Yeast diversity in the Mediterranean strawberry tree (Arbutus unedo L.) fruits' fermentations. Food Res. Int. 2012, 47, 45-50. [CrossRef]

7. Caldeira, I.; Gomes, F.; Botelho, G. Arbutus unedo L. spirit: Does the water addition before fermentation matters? In Proceedings of the 1st International Congress on Engineering and Sustainability in the XXI Century-INCREaSE 2017; Mortal, A., Aníbal, J., Monteiro, J., Sequeira, C., Semião, J., Silva, M.M., Oliveira, M., Eds.; Springer: Berlin/Heidelberg, Germany, 2018; pp. 206-215.

8. Cavaco, T.; Longuinho, C.; Quintas, C.; Saraiva de Carvalho, I. Chemical and microbial changes during the natural fermentation of strawberry tree (Arbutus unedo L.) fruits. J. Food Biochem. 2007, 31, 715-725. [CrossRef]

9. Wormit, A.; Usadel, B. The Multifaceted role of pectin methylesterase inhibitors (PMEIs). Int. J. Mol. Sci. 2018, 19, 2878. [CrossRef]

10. Pang, X.-N.; Li, Z.-J.; Chen, J.-Y.; Gao, L.-J.; Han, B.-Z. A comprehensive review of spirit drink safety standards and regulations from an international perspective. J. Food Prot. 2017, 80, 431-442. [CrossRef]

11. Regulation EU n ${ }^{\circ}$ 2019/787 of the European Parliament and of the Council of 17 April 2019 on the definition, description, presentation and labelling of spirit drinks, the use of the names of spirit drinks in the presentation and labelling of other foodstuffs, the protection of geographical indications for spirit drinks, the use of ethyl alcohol and distillates of agricultural origin in alcoholic beverages, and repealing Regulation (EC) No 110/2008. Off. J. Eur. Union 2019, L130, 1-54.

12. Caldeira, I.; Gomes, F.; Mira, H.; Botelho, G. Distillates composition obtained of fermented Arbutus unedo L. fruits from different seedlings and clonal plants. Ann. Agric. Sci. 2019, 64, 21-28. [CrossRef]

13. Anjos, O.; Campos, M.G.; Ruiz, P.C.; Antunes, P. Application of FTIR-ATR spectroscopy to the quantification of sugar in honey. Food Chem. 2015, 169, 218-223. [CrossRef] [PubMed]

14. Estevinho, L.M.; Feás, X.; Seijas, J.A.; Vázquez-Tato, M.P. Organic honey from Trás-os-Montes region (Portugal): Chemical, palynological, microbiological and bioactive compounds characterization. Food Chem. Toxicol. 2012, 50, 258-264. [CrossRef] [PubMed]

15. El Sohaimy, S.A.; Masry, S.H.D.; Shehata, M.G. Physicochemical characteristics of honey from different origins. Ann. Agric. Sci. 2015, 60, 279-287. [CrossRef]

16. Adeboye, A.S.; Babajide, J.M.; Shittu, T.A.; Omemu, A.M.; Oluwatola, O.J. Effect of honey as partial sugar substitute on pasting properties, consumer preference and shelf stability of cassava-wheat composite bread. Niger. Food J. 2013, 31, 13-22. [CrossRef]

17. Pascoal, A.; Oliveira, J.M.; Pereira, A.P.; Féas, X.; Anjos, O.; Estevinho, L.M. Influence of fining agents on the sensorial characteristics and volatile composition of mead. J. Inst. Brew. 2017, 123, 562-571. [CrossRef]

18. Pascoal, A.; Anjos, O.; Feás, X.; Oliveira, J.; Estevinho, M.L. Impact of fining agents on the volatile composition of sparkling mead. J. Inst. Brew. 2019, 125, 125-133. [CrossRef]

19. Anjos, O.; Santos, R.; Estevinho, L.M.; Caldeira, I. FT-RAMAN methodology for the monitoring of honeys' spirit distillation process. Food Chem. 2020, 305, 125511. [CrossRef]

20. Ávila, S.; Beux, M.R.; Ribani, R.H.; Zambiazi, R.C. Stingless bee honey: Quality parameters, bioactive compounds, health-promotion properties and modification detection strategies. Trends Food Sci. Technol. 2018, 81, 37-50. [CrossRef]

21. Pereira, A.P.; Dias, T.; Andrade, J.; Ramalhosa, E.; Estevinho, L.M. Mead production: Selection and characterization assays of Saccharomyces cerevisiae strains. Food Chem. Toxicol. 2009, 47, 2057-2063. [CrossRef]

22. Pereira, A.P.; Mendes-Ferreira, A.; Oliveira, J.M.; Estevinho, L.M.; Mendes-Faia, A. High-cell-density fermentation of Saccharomyces cerevisiae for the optimisation of mead production. Food Microbiol. 2013, 33, 114-123. [CrossRef] [PubMed]

23. Mendes-Ferreira, A.; Cosme, F.; Barbosa, C.; Falco, V.; Inês, A.; Mendes-Faia, A. Optimization of honey-must preparation and alcoholic fermentation by Saccharomyces cerevisiae for mead production. Int. J. Food Microbiol. 2010, 144, 193-198. [CrossRef] [PubMed]

24. Pino, J.A.; Fajard, M. Volatile composition and key flavour compounds of spirits from unifloral honeys. Int. J. Food Sci. Technol. 2011, 46, 994-1000. [CrossRef]

25. Anjos, O.; Frazão, D.; Caldeira, I. Physico-chemical and sensorial characterization of honey spirits. Foods 2017, 6, 58. [CrossRef]

26. Da Porto, C. Grappa and grape-spirit production. Crit. Rev. Biotechnol. 1998, 18, 13-24. [CrossRef] 
27. OIV. Compendium of International Methods of Analysis of Spirituous Beverages of Vitivinicultural Origin; OIV: Paris, France, 2014.

28. Luís, A.C.M.; Mota, D.; Anjos, O.; Caldeira, I. Single-laboratory validation of determination of acetaldehyde, ethyl acetate, methanol and fusel alcohols in wine spirits, brandies and grape marc spirits using GC-FID. Cienc. Tec. Vitivinic. 2011, 26, 69-76.

29. Sensory Analysis-General Guidelines for the Selection, Training and Monitoring of Selected Assessors and Expert Sensory Assessors; ISO Standard 8586; International Organization for Standardization: Genève, Switzerland, 2012.

30. Sensory Analysis_-Apparatus-Wine-Tasting Glass; ISO Standard 3591; Last Reviewed in 2010; International Organization for Standardization: Genève, Switzerland, 1977.

31. Diário da República I; Série A, 223; Decreto Lei $n^{\circ}$ 238/2000 de 26 de Setembro; Imprensa Nacional: Lisboa, Portugal, 2000; pp. 5145-5147.

32. Anjos, O.; Iglesias, C.; Peres, F.; Martínez, J.; García, Á.; Taboada, J. Neural networks applied to discriminate botanical origin of honeys. Food Chem. 2015, 175, 128-136. [CrossRef]

33. Prasanna, V.; Prabha, T.N.; Tharanathan, R.N. Fruit ripening phenomena-An overview. Crit. Rev. Food Sci. Nutr. 2007, 47, 1-19. [CrossRef]

34. Zocca, F.; Lomolino, G.; Curioni, A.; Spettoli, P.; Lante, A. Detection of pectinmethylesterase activity in presence of methanol during grape pomace storage. Food Chem. 2007, 102, 59-65. [CrossRef]

35. Cortés, S.; Rodríguez, R.; Salgado, J.M.; Domínguez, J.M. Comparative study between Italian and Spanish grape marc spirits in terms of major volatile compounds. Food Control 2011, 22, 673-680. [CrossRef]

36. Zhang, H.; Woodams, E.E.; Hang, Y.D. Factors Affecting the methanol content and yield of plum brandy. J. Food Sci. 2012, 77, 79-82. [CrossRef] [PubMed]

37. Roldán, A.; Muiswinkel, G.C.J.; Lasanta, C.; Palacios, V.; Caro, I. Influence of pollen addition on mead elaboration: Physicochemical and sensory characteristics. Food Chem. 2011, 126, 574-582. [CrossRef]

38. Giovane, A.; Servillo, L.; Balestrieri, C.; Raiola, A.; D’Avino, R.; Tamburrini, M.; Ciardiello, M.A.; Camardella, L. Pectin methylesterase inhibitor. BBA-Proteins Proteom. 2004, 1696, 245-252. [CrossRef] [PubMed]

39. Małgorzata, D.; Dorota, G.-L.; Sylwia, S.; Monika, T.; Sabina, B.; Ireneusz, K. Physicochemical quality parameters, antibacterial properties and cellular antioxidant activity of Polish buckwheat honey. Food Biosci. 2020, 34, 100538.

40. Christoph, N.; Bauer-Christoph, C. Flavour of spirit drinks: Raw materials, fermentation, distillation, and ageing. In Flavour Fragances; Berger, R.G., Ed.; Springer: Berlin/Heidelberg, Germany, 2007; pp. $219-225$.

41. Ribéreau-Gayon, P.; Dubourdieu, D.; Donèche, B.; Lonvaud, A. Handbook of Enology: The Microbiology of Wine and Vinifications, 2nd ed.; Wiley: Talence, France, 2006.

42. Lee, K.Y.M.; Paterson, A.; Piggott, J.R.; Richardson, G.D. Origins of flavour in whiskies and a revised flavour wheel: A review. J. Inst. Brew. 2001, 107, 287-313. [CrossRef]

43. Caldeira, I.; Belchior, A.P.; Clímaco, M.C.; Bruno de Sousa, R. Aroma profile of Portuguese brandies aged in chestnut and oak woods. Anal. Chim. Acta 2002, 458, 55-62. [CrossRef]

(C) 2020 by the authors. Licensee MDPI, Basel, Switzerland. This article is an open access article distributed under the terms and conditions of the Creative Commons Attribution (CC BY) license (http://creativecommons.org/licenses/by/4.0/). 